\title{
An exploratory study comparing three work-rest schedules during simulated repetitive precision work
}

Liuxing Tsao ${ }^{1,2,3}$, Sunwook Kim ${ }^{1}$, Liang $\mathrm{Ma}^{2}$, and Maury A. Nussbaum ${ }^{1, *}$

${ }^{1}$ Department of Industrial and Systems Engineering, Virginia Tech, Blacksburg, VA 24061, USA

${ }^{2}$ Department of Industrial Engineering, Tsinghua University, 100084, Beijing, China

${ }^{3}$ Teaching Center for Writing and Communication, School of Humanities, Tsinghua University, 100084, Beijing, China

Corresponding Author:

Dr. Maury A. Nussbaum

Department of Industrial and Systems Engineering, Virginia Tech, Blacksburg, VA 24061, USA nussbaum@vt.edu, (001)-540-231-6053 


\begin{abstract}
The pattern of work and rest can influence both physical fatigue and task performance in manual operations. However, there is relatively limited evidence regarding the influences of specific work/rest schedules in tasks requiring high repetitiveness and precision demands, along with relatively low exertion levels. Eighteen participants completed an exploratory study that simulated such tasks, to compare the effects of three distinct work/rest schedules (i.e., short frequent [short] and long infrequent breaks [long], and a self-selected schedule) on muscle fatigue, task performance (in terms of accuracy and speed), and preference. Schedules with long or self-selected breaks generally induced less muscle fatigue, compared with the short break condition. Participants preferred the self-selected condition the most and the long-break condition the least. The different schedules tested did not influence task performance. A selfselected schedule may be beneficial for repetitive precision task, to achieve a balance across muscle fatigue, task performance, and individual preference.

\section{Practitioner Summary}

Influences of three work/rest schedules (i.e., short and long breaks, and a self-selected schedule) on fatigue, performance, and preference were explored during repetitive precision tasks. Schedules with long or self-selected breaks induced less muscle fatigue and none of the three schedules influenced performance. A self-selected schedule was the most preferred.
\end{abstract}

\title{
Keywords:
}

Repetitive task; Precision task; Muscle fatigue; Performance 


\section{Introduction}

Musculoskeletal disorders (MSDs) remain an important concern around the world. In 2018 for example, among the occupational injuries and illness causing DAFW (days away from work) cases in the U.S. private sector, 30\% were MSD-related (Bureau of Labor Statistics, 2020). The European Agency for Safety and Health at Work also reported that work-related MSDs are the most prevalent work-related health problem (de Kok et al., 2019). Among several adverse effects, work-related MSDs can lead to diverse occupational disabilities (Crook et al., 2002).

Excessive muscle requirements are considered an antecedent of MSDs (Armstrong et al., 1993), and can also lead to fatigue and reduced worker performance. One review indicated that operator fatigue and workload factors mediate the relationship between inadequate ergonomic design and decreased system performance (Neumann et al., 2016). As one example, we examined the effects of wrist fatigue on specific motor skills (i.e., stability and dexterity), finding that fatigue reduced critical motor skills of operators that are required for fine assembly tasks (Tsao et al., 2017). In a similar context, a recent study explored the relationship between task performance and physical and cognitive fatigue, supporting that measures of fatigue share a similar pattern with changes in work performance, and that there was an association between fatigue and work performance (Yung et al., 2017). 
Various work patterns have been studied to evaluate their influence on fatigue. Task parameters, such as the workload level (Ivarsson \& Eek, 2016; Rosa et al., 1998), the temporal variation of specific workloads (Dickerson et al., 2015; Luger et al., 2017; Paquet \& Nirmale, 2004; Yung et al., 2012, 2014), and the activity/workload variation of tasks (Balogh et al., 2016; Falla \& Farina, 2007; Luger et al., 2015, 2016) have been found to affect fatigue development. Work pace, for instance, influences workload, fatigue, and motor variability (Januario et al., 2018; Srinivasan et al., 2015; Bosch et al., 2011). Both active (voluntary) and passive (scheduled) pauses also influence fatigue development and motion variability (Crenshaw et al., 2006; Samani et al., 2009, 2010). Job rotation models and guidelines based on pre-determined exposure levels have been introduced to reduce fatigue and subsequent adverse effects (Bechtold, 1991; Mathiassen \& Winkel, 1992; Rajabalipour Cheshmehgaz et al., 2012; Yoon et al., 2016). However, the specific influences of interventions related work patterns have been found to be inconsistent (e.g., see reviews by Leider et al., 2015 and Padula et al., 2017 for the influence of job rotation; Luger et al., 2014 and Lu et al., 2021 for the influence of task variation; and Januario et al., 2016 for the influence of active pauses).

The effects of work patterns on task performance (e.g., speed and accuracy) also have been evaluated in previous studies, though the findings were also somewhat inconsistent. For example, Henning et al. (1989) found that introducing a longer rest period led to a lower correction rate (i.e., better accuracy) than a short rest duration during a two-day repetitive typing 
task. However, Balci \& Aghazadeh (2003) observed the fastest speed and the highest accuracy in a data entry task when the work cycle and the rest periods were short and frequent. Rashedi \& Nussbaum (2016) also reported superior force steadiness in shorter (30s) vs. longer work cycles (60s) during intermittent muscle contractions. Further, Park et al. (2017) found that active exercise during short breaks were beneficial to surgeon performance and mental focus. Meanwhile, other researchers have reported no significant influences of work patterns on task performance. McLean et al. (2001) evaluated the effects of task duration or rest periods on typing task productivity, but found no significant difference in output. In surgical tasks, Komorowski et al. (2015) and Hallbeck et al. (2017) reported no significant influences of work/rest schedules on surgical precision.

Among several alternative work patterns, the use of micro-breaks has been considered by several investigators. Micro-breaks are short, but relatively frequent rest periods, given in between physical tasks to provide rest and recovery. A review of relevant studies using micro-breaks to reduce fatigue during various tasks was provided by Vijendren et al. (2020). To summarize, implemented breaks have ranged from 6 to 120 seconds, with most between 20 and 30 seconds. Regardless of the specific type of implemented rest (e.g., active, passive, or guided exercises), benefits were generally evident in terms of reduced discomfort and fatigue. Byström et al. (1991) hypothesized that introducing micro-breaks could postpone the subjective feeling of fatigue, which may mistakenly lead participants to work excessively and thereby indirectly increase the 
risk of MSD. Overall, existing evidence suggests that micro-breaks do not adversely influence task performance.

For highly-repetitive tasks, such as in light assembly, it thus appears that using short/microbreaks could be a promising intervention for reducing upper-extremity fatigue, although a majority of earlier studies have focused on surgical (Dorion \& Darveau, 2013; Hallbeck et al., 2017; Komorowski et al., 2015; Park et al., 2017) or video display terminal tasks (Chaikumarn et al., 2018; Henning et al., 1989; McLean et al., 2001; Sundelin \& Hagberg, 1989). Note that the U.S. Occupational Safety and Health Administration suggests introducing short/micro breaks when work involves static postures or is highly repetitive (OSHA, 2001, 2003). We are particularly interested in electronic assembly lines, in which tasks have somewhat distinct characteristics, including very high repetitiveness and precision demands, together with fairly low required exertion levels. Even when the level of physical exertion is relatively low, there is evidence that prolonged intermittent contractions can cause physical fatigue and potentially increase the risk of worker injury (Dennerlein et al., 2003; Gates \& Dingwell, 2008; Søgaard et al., 2003; Visser et al., 2004). Additional behavioral and physiological changes may also decrease operator well-being (Mehta et al., 2015). While many strenuous manual material handling tasks are being replaced by machines, some repetitive, high-precision, and low-demand tasks remain difficult to automate. We assume that such tasks are likely to be completed manually in the future, due to the benefits of human dexterity and flexibility (Ivarsson \& Eek, 
2016; Mathiassen, 2006). As such, additional investigation of the effects of different types of short/micro-breaks was considered warranted.

We completed an exploratory study to compare the effects of three distinct work/rest schedules in the context of repetitive precision tasks. The three schedules involved fixed intervals of short frequent and long infrequent breaks, along with a schedule in which breaks were self-selected; in all three cases, the total amount of work and rest was identical. Each of the schedules was evaluated in terms of muscular fatigue, task performance (accuracy and speed), and preference. Based on existing evidence, we anticipated that the use of short and frequent work breaks would lead to less fatigue or enhanced recovery compared with long and infrequent work breaks (Lin et al., 2012; Rashedi \& Nussbaum, 2016; Wawrow et al., 2011). We also expected that a selfselected schedule would be preferred by the participants, due to the higher level of control it provided (Luger et al., 2016; Stålhammar et al., 1992). Given ambiguous findings in previous studies, a substantial influence of work/rest schedules on performance was considered unlikely. Furthermore, previous evidence has highlighted gender differences in muscle fatigability and muscle motor recruitment strategies (Clark et al., 2003; Endo \& Kawahara, 2011; Rashedi \& Nussbaum, 2016; Srinivasan et al., 2016). Based on earlier findings (Endo \& Kawahara, 2011; Horton et al., 2012), we expected females would experience less muscle fatigue and smaller effects of fatigue on task performance. 


\section{Methods}

\subsection{Participants}

A convenience sample of 18 healthy and young volunteers (gender-balanced) completed the experiment. None had any current or recent ( 12 months) MSDs or injuries, and their demographic information is summarized in Table 1. All participants provided informed consent, and the experimental protocols were approved by the Virginia Tech Institutional Review Board (IRB \#18-608).

Table 1. Mean (SD) participant characteristics $(\mathrm{BMI}=$ body mass index)

\begin{tabular}{lcccc}
\hline Gender & $\begin{array}{c}\text { Age } \\
(\text { years })\end{array}$ & $\begin{array}{c}\text { Stature } \\
(\mathbf{c m})\end{array}$ & $\begin{array}{c}\text { Body Mass } \\
\mathbf{( k g )}\end{array}$ & $\begin{array}{c}\text { BMI } \\
\left(\mathbf{k g} / \mathbf{m}^{2}\right)\end{array}$ \\
\hline Female $(n=9)$ & $24.9(3.5)$ & $163.3(7.3)$ & $58.6(8.2)$ & $22.0(3.2)$ \\
Male $(n=9)$ & $26.3(4.1)$ & $173.2(5.5)$ & $71.4(7.2)$ & $23.8(2.3)$ \\
\hline Total & $25.1(3.9)$ & $168.3(8.1)$ & $65.0(9.9)$ & $22.9(2.9)$ \\
\hline
\end{tabular}

\subsection{Experimental Design}

\section{$\underline{\text { Repetitive Task Simulations }}$}

The current study included activities used in our previous work; as such, a brief overview is given here, with more details provided in our earlier report (Tsao et al., 2020). A simulated repetitive task was used with a cycle time of $\sim 15$ seconds, and each cycle is termed a "replication" hereafter. Replications consisted of two sub-tasks to represent typical skills and activities required in precision assembly lines (Figure 1): 1) maze tracking (5 seconds), simulating tasks that require stability and precision; and 2) an assembly/disassembly task (10 seconds), representing tasks that require manual dexterity. Maze tracking was completed using a stylus on a tablet (Galaxy Tab2 P5110, resolution $=800$ x 1280 pixels, Samsung Electronics Co., Ltd., South Korea), while assembly/disassembly was done using the Purdue Pegboard (Model 
32020A, Lafayette, IN, USA). Periods of one-half-second were included between the two subtasks to allow for transitions between each. All testing was done in a laboratory environment (Figure 2), which was kept consistent for all participants (i.e., temperature, lighting, and noise level).

\section{Remaining Reps: 160 Remaining Rest Time: 240s}

Bo!

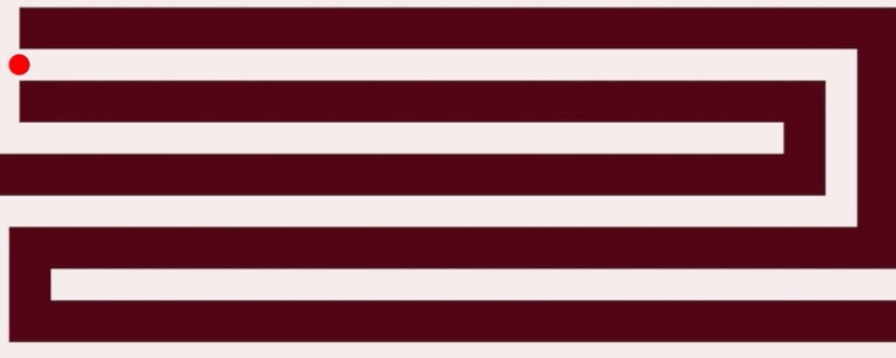

Rep: 1 Time: $2.538 \mathrm{~s}$ Finished: 0 Errors: 0

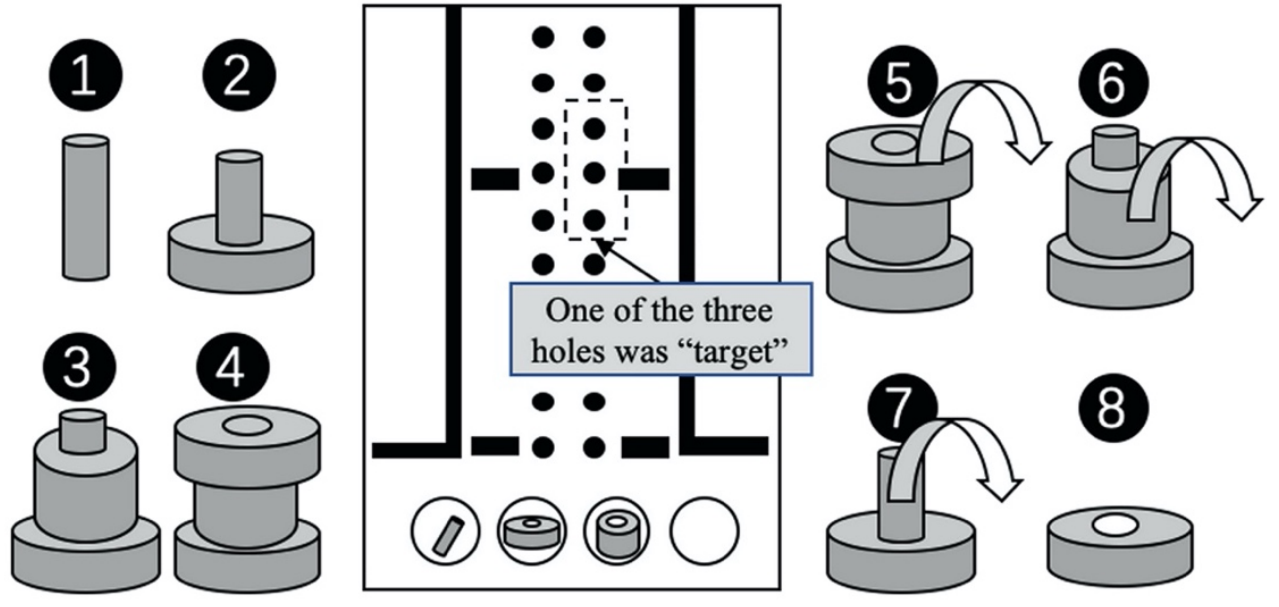

Figure 1. Illustrations of the two experimental sub-tasks; completing both sub-tasks comprised one 'work replication'. Top: maze tracking with display of remaining number of work replications and rest duration. Bottom: assembly/disassembly. For the latter, the eight distinct and sequential movements are indicated. 


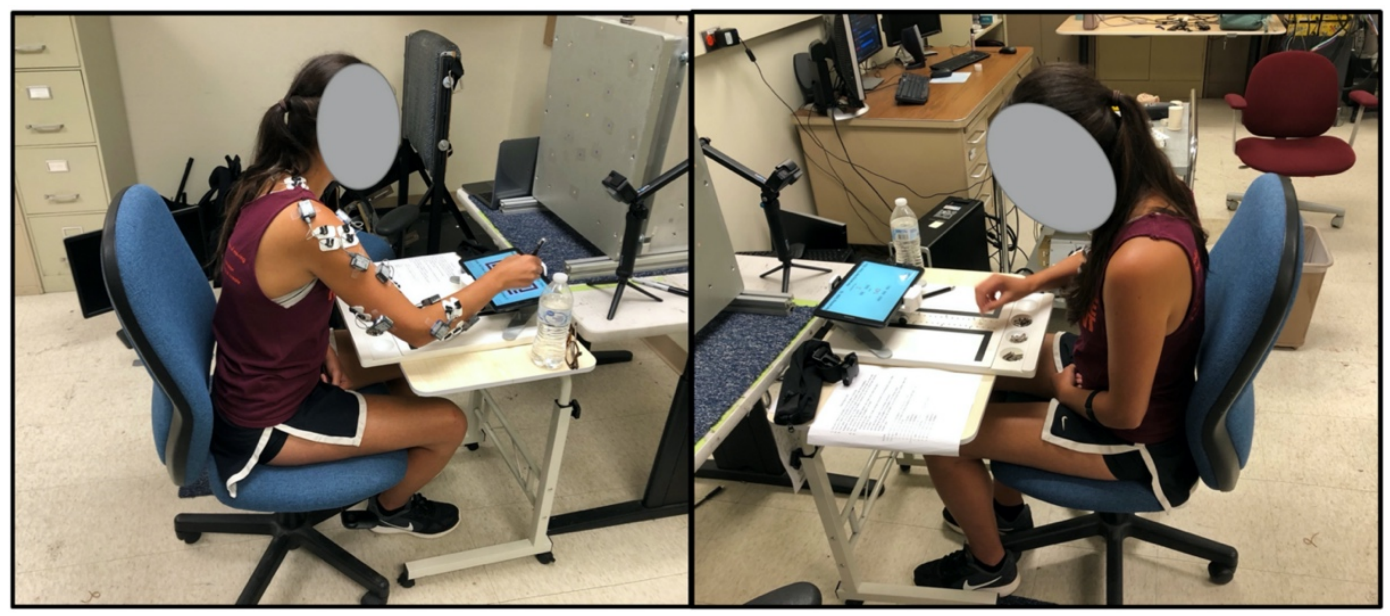

Figure 2. Configuration of the experiment. Left: participant doing maze tracking, showing surface EMG sensors on the dominant arm. Right: participant doing the assembly/disassembly task.

\section{Work/Rest (W/R) Schedules}

Participants completed multiple replications of the task under three W/R schedules, which included: 1) Long, infrequent rest breaks (“Long”); 2) Short, frequent rest breaks (“Short”); or 3) a Self-selected schedule, in which participants determined the frequency and the duration of rest breaks ("Self-selected"). Specific aspects of the W/R schedules, as subsequently described, were based on both existing literature and our previous study (Tsao et al., 2020). In each W/R schedule, the total work duration was 40 minutes. This specific duration was based on our earlier results (Tsao et al., 2020), which indicated that participants could maintain stable performance for 40 minutes of work without extreme fatigue or physical discomfort. Total rest duration was based on our field observations in an electronic production factory, wherein workers usually work for two hours before getting a 10 to 15 -minute rest period, yielding a $\mathrm{W} / \mathrm{R}$ ratio of $\sim 12: 1$ to 8:1. To reflect this, a total rest time of four minutes was provided during the 40 -minute work periods, resulting in a $\mathrm{W} / \mathrm{R}$ ratio of $10: 1$. 
In all three $\mathrm{W} / \mathrm{R}$ schedules, participants needed to work (do the repetitive task) for 40 minutes (160 replications) and had a total resting time of four minutes. The three schedules differed, though, in how the resting time was distributed. In the Long-break condition, participants worked for 20 minutes ( 80 replications) then had a rest break of 120 seconds, and this pattern was repeated once more (Figure 3A). In the Short-break condition, rest periods of 30 seconds were provided after every 5 minutes of work, with this pattern completed a total of eight times (Figure 3B). The noted rest duration was chosen since $20-30$ seconds is a common duration that has been used in previous studies (Dorion \& Darveau, 2013; Genaidy et al., 1995; Henning et al., 1989; McLean et al., 2001; Vijendren et al., 2020). In the Self-selected condition, rest breaks were taken according to a participant's preferences regarding when and how long to rest (Figure 3C). Feedback ensured that participants worked for a total of 40 minutes in this condition and that the total duration of rest was limited to four minutes. Specifically, the remaining rest time and remaining work replications were both displayed on the tablet during the maze and assembly tasks (see Figure 1). All the three schedules included a final rest period after the $160^{\text {th }}$ replication (i.e., 120 seconds in the Long-break condition, 30 seconds in the Short-break condition, and the remaining of the 4 minutes in the Self-selected condition); this final period was included to complete the last replication. 
$\mathbf{A}$

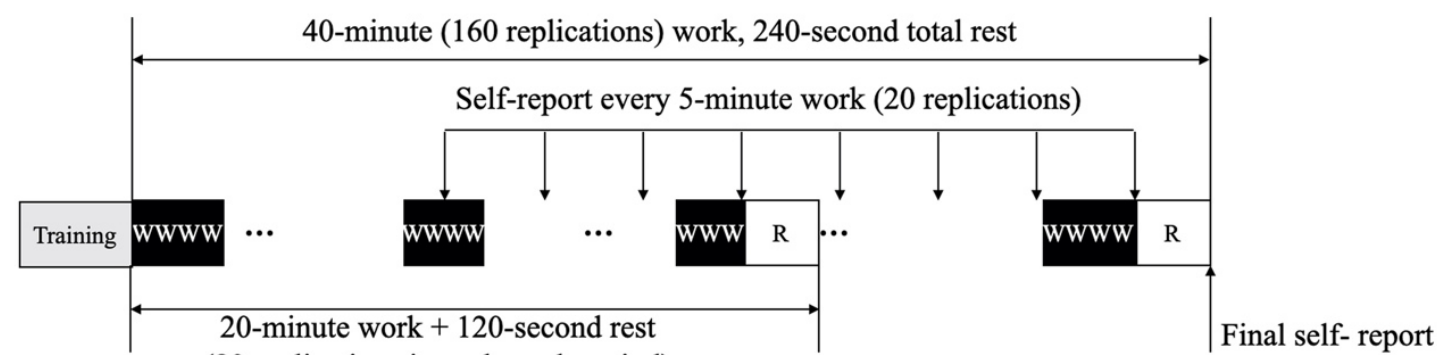

(80 replications in each work period)

$\begin{array}{ll}\text { W } & \begin{array}{l}\text { Work } \\ \text { replication }\end{array}\end{array}$

B

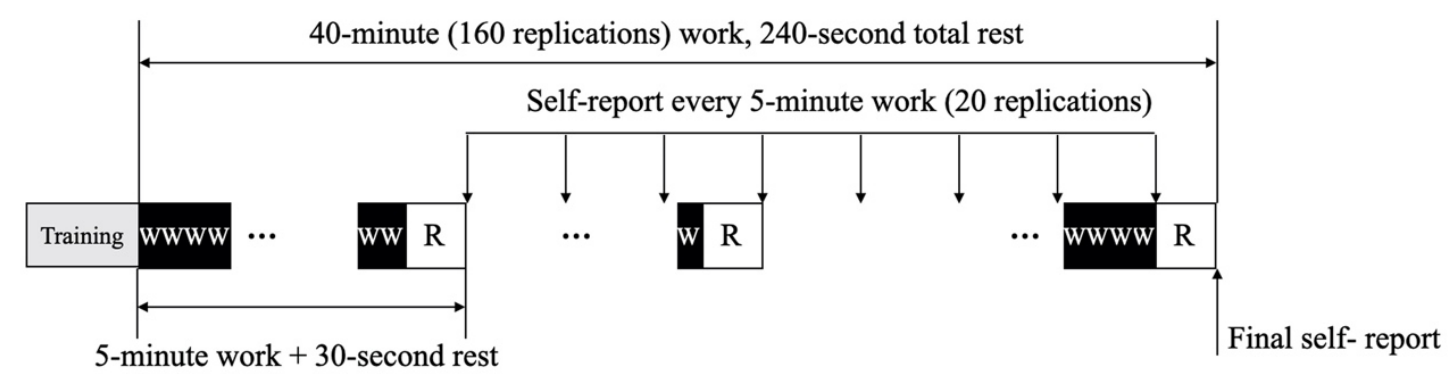

(20 replications in each work period)

w $\begin{aligned} & \text { Work } \\ & \text { replication }\end{aligned}$

$\mathbf{C}$

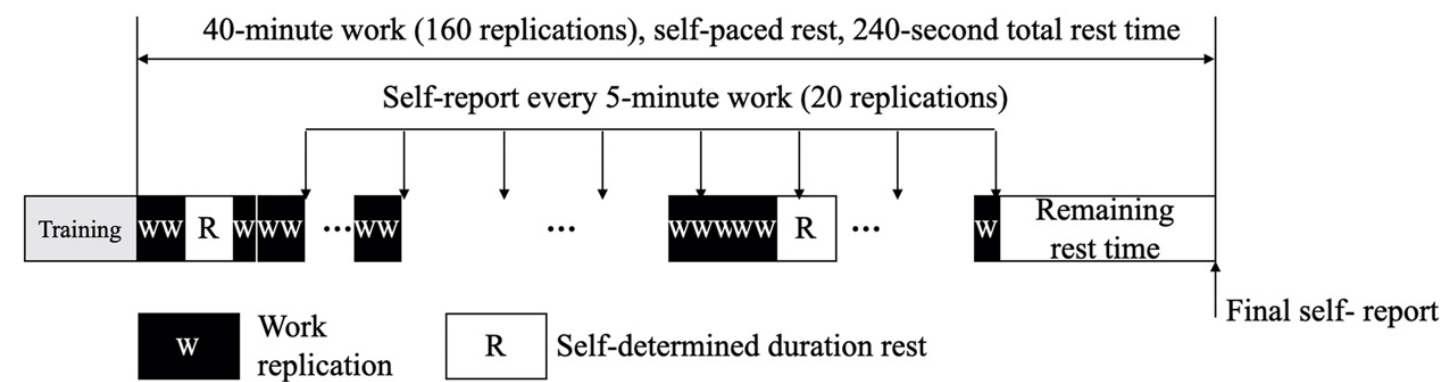

Figure 3. Illustration of the three work/rest schedules included in the study. A: Long, infrequent rest breaks; B: Short, frequent rest breaks; and C: Self-selected rest break frequency and duration. Note that the latter varied between participants, and the illustration is provided only as an example. 


\section{Experimental procedures}

Each participant completed the experiment in two sessions. These sessions were either completed in a single day or in two separate days, depending on the availability of a given participant. For the former, the two sessions were separate by at least four hours to facilitate recovery and minimize any residual fatigue. The presentation order of the three W/R schedules was counterbalanced across participants using multiple 3x3 balanced Latin Squares.

In the first session, participants were familiarized with and practiced the task, and then completed the $1^{\text {st }} \mathrm{W} / \mathrm{R}$ condition. Demographic and anthropometric information was obtained initially. A seated workstation (desk and chair) was then configured to a given participant (Figure 2), such that the work surface was at seated elbow height, and the chair height placed the feet were on the floor and the knee joints at $\sim 90^{\circ}$. The Purdue Pegboard was placed on the worksurface, oriented horizontally, whereas the tablet was set at $\sim 15^{\circ}$ below the horizontal. Participant seated eye height was recorded after the workstation was configured, and was then duplicated in the second session. After measuring a participant's elbow-to-fist length, one hole in the Purdue Pegboard was selected as the "target" hole for use during assembly/disassembly.

Subsequently, participants were instrumented with surface electromyography (sEMG) sensors to monitor muscle activation. Pairs of bipolar electrodes were placed over 10 arm muscle groups in the self-reported dominant upper extremity. Specific muscles were selected that were accessible to surface monitoring and that were active in the simulated task: extensor carpi radialis (ECR), extensor carpi ulnaris (ECU), flexor carpi ulnaris (FCU), flexor carpi radialis (FCR), biceps brachii (BB), triceps brachii medial (TB), anterior deltoid (AD), medial deltoid (MD), posterior 
deltoid (PD), and upper trapezius (UT). Skin preparation and sensor placement followed guidelines provided by SENIAM (Hermens et al., 2000).

Participants then practiced the simulated task for 20 minutes followed by a 10-minute rest period, by repeating the 15 -second replications (maze tracking + assembly/disassembly). Note that this task duration was based on pilot results showing that after 10-minutes of training (i.e., 40 replications) participants could reach target performance levels (i.e., complete both tasks in pre-set times: maze-tracking for 5 seconds and assembly/disassembly for 10 seconds). An extended duration of 20 minutes was included to ensure the participants could both reach the target performance and experience the longest duration they would work in the three W/R schedules. During the practice, participants were also familiarized with providing intermittent ratings of perceived discomfort (RPDs), using the Borg (1998) CR-10 scale (see Sood et al., 2007).

Formal data collection in the $1^{\text {st }} \mathrm{W} / \mathrm{R}$ condition started after a brief introduction to the specific schedule. Participants were instructed to complete the simulated tasks as accurately and as rapidly as possible, but with task accuracy as the primary objective. No additional verbal encouragement or instructions were provided during the simulated task. The first session ended after the participant completed the first W/R condition.

In the second session, initiated at least four hours after the first session, participants completed the $2^{\text {nd }}$ and the $3^{\text {rd }} \mathrm{W} / \mathrm{R}$ conditions. They were first instrumented with the noted sensors and the workstation was configured as in the first session. A shorter practice time of 10 minutes (40 
replications) with a 10-minute rest was given to help recall the task. Participants then completed the $2^{\text {nd }}$ and $3^{\text {rd }} \mathrm{W} / \mathrm{R}$ conditions (each condition for 160 work replications and 4-minute rest), each proceeded by an introduction to the specific schedule and with at least 20 minutes for recovery between conditions. To enhance the likelihood of recovery, additional rest was provided if Borg CR-10 ratings were not 0 for each of the body parts noted below.

Throughout each W/R condition, video recordings were obtained, and raw sEMG data were amplified and sampled $(1,500 \mathrm{~Hz})$ using a wireless system (DTS, Noraxon Inc., Scottsdale, AZ, USA). After every five minutes of work (20 replications), participants provided RPDs of the neck, shoulder, upper arm, forearm, and hand/wrist. These RPDs were also obtained after the final rest period was completed. After completing all three W/R schedules, participants were asked to rank order their preferences for these schedules and to comment on the strategy they used to allocate rest periods during the Self-selected schedule. Note that participants were allowed to stop performing the tasks if they experienced substantial discomfort, though all schedules were completed by all participants.

\subsection{Data Processing and Dependent Measures}

Data from each muscle were initially segmented within the $\sim 15$-second work period in each replication. Raw EMG data were bandpass filtered (bidirectional, $4^{\text {th }}$ order, Butterworth, 20-500 $\mathrm{Hz}$ ). Then, the median power frequency (MdPF) was calculated using a sliding window of 500 ms duration, which corresponded roughly to the mean movement duration during the assembly/disassembly task. A window overlap of $20 \%$ was used, based on prior work (Mark Burden et al., 2014). Median values of MdPF for each muscle were obtained within each 
replication as a dependent measure reflecting localized muscle fatigue; specifically, a lower value indicates more fatigue (Al-Mulla et al., 2011; Merletti \& Farina, 2016; Phinyomark et al., 2012). To facilitate comparisons between schedules and participants, MdPF measures were normalized to mean values obtained in the first four replications $(\sim 1 \mathrm{~min})$ of a given W/R schedule.

Task performance in each cycle was assessed in terms of accuracy and speed. Task accuracy (termed "Errors" hereafter) was determined based on errors that occurred in each of the two subtasks. During maze tracking, errors were defined as the number of times the stylus touched any "wall" along the path. During the assembly/disassembly task, errors were defined as: dropping a part; picking a part from the wrong container or putting it away to the wrong container; using the wrong order of assembly/disassembly; or placing the assembly in a hole other than the "target" one. Task speed was measured in the maze tracking task as the total path length completed, whereas the speed of assembly/disassembly was measured as the number of successful movements completed (of a maximum of eight). Note that the "speed" here was likely to have a truncated distribution. Specifically, different participants would exhibit the same speed if they finished all required movements within the fixed time limit, regardless of any differences in the time remaining. This approach, though, was used to be consistent with task characteristics in reality, in which a maximum speed often exists (i.e., a task is finished within a time limit). Performance measures for maze tracking were determined from a custom application, while measures for the assembly/disassembly task were derived from viewing the video recordings. Four dependent measures were evaluated for each task replication: maze tracking errors $(0+)$; 
maze tracking speed $(0-4200$ pixels); assembly/disassembly errors $(0+)$; and assembly/disassembly speed $(0-8)$.

MdPF and task performance measures were obtained for each of the 160 replications in each of the three W/R schedules. An overall comparison of MdPF and performance was completed based on a compilation across the 160 replications. As in earlier work (e.g., Horton et al., 2012), we did not examine temporal trends in these measures, since each schedule involved different timings of work and rest, and different accumulated work and rest over time. To determine whether median values or mean values should be used as a summary measure, the Shapiro-Wilk test was used to test whether a normal distribution was appropriate for each MdPF and performance measure across the 160 replications. The null hypothesis of a normal distribution could not be rejected for most MdPF values (10 muscles) for each participant and W/R schedule. These measures also had skewness values $\sim 0$. In contrast, the four performance measures were typically not normally distributed. Therefore, median values across the 160 replications for each participant in each work/rest schedule were analyzed as outcome measures when comparing the overall influence of W/R schedule on MdPF and task performance.

\subsection{Data Analysis}

Separate mixed-factor analyses of variance (ANOVAs) were used to evaluate the overall effects of Schedule and Gender on median values of MdPF and task performance measures. The order of presentation of the three schedules was included as a blocking factor. We also analyzed these measures in periods immediately prior to and after a rest break. The former included $\sim 15$ seconds of data for MdPF and 1 replication for the performance measures. For the 160th replication, only 
data prior to a rest period were included in the analysis. These analyses were intended to respectively assess the accumulated effects of fatigue and the recovery achieved after rest. Together with the overall effects of fatigue, these analyses also provided information to assess whether fatigue had been induced in all three schedules. Separate analyses of covariance (ANCOVAs) were used to assess the effect of Schedule and Gender, with order again included as a blocking factor and with Time as the covariate (quantified as the number of completed replications prior to the start of a given rest period).

RPDs were obtained at fixed intervals in each schedule. As noted above, these were used primarily to assess whether participants could continue the task (e.g., not excessively fatigue). We did not analyze RPDs during each schedule, for the same reasons provided earlier (e.g., different accumulated work and rest). Instead, only the final RPD rates were analyzed (after completing 40 minutes of total work and four minutes of total rest), using the same ANOVA model noted earlier.

Rankings of the three work/rest schedules were assessed using the non-parametric Wilcox Rank Sum test, and the Ridit (relative to an identified distribution unit) analysis was used to compare between levels. Comments on the strategies used by participants to allocate work and rest during the Self-selected schedule were analyzed qualitatively.

All statistical tests were executed using R Studio (version 1.3.1073, R studio Inc., MA, U.S.A.) in the R software package (version 4.0.2) (R Core Team, 2020). The lme function (linear mixed effect) in the nlme package, with the REML method, was used to fit ANOVA/ANCOVA models, 
and no substantial deviations from model assumptions were evident. In particular, residual plots were examined to ensure no substantial violations of ANOVA/ANCOVA model assumptions. Statistical significance was concluded when $p<0.05$, though given the exploratory nature of the study, several effects that approached significance are also highlighted. Post hoc simple-effects tests and paired comparisons (Tukey's HSD) were conducted where relevant.

To explore the strategies that participants used to allocate rest periods during the Self-selected schedule, we completed an informal analysis of the brief comments (2-3 sentences) provided by each participant about their work/rest strategies (i.e., focusing on words/comments related to 'fatigue/discomfort', 'performance', and 'pace'). Comparisons of the overall, prior-to-break, and after-break outcome measures provided information to help understand the participants' strategies in the Self-selected schedule. 


\section{Results}

\subsection{Overall Effects of Schedule and Gender}

Descriptive statistics and ANOVA results for normalized MdPF are provided in Table A1 in the Appendix. These results indicate that, overall, all three schedules induced localized muscle fatigue (i.e., normalized MdPF values $<1$ ). For most muscles, values were higher in the Longbreak and Self-selected conditions, suggesting less fatigue, though differences were quite small and there were no significant main or interactive effects of Schedule or Gender for any of the muscles. Performance measures are summarized in Table A2. There were again no significant main or interactive effects of Schedule or Gender, and differences between conditions were small.

\subsection{Effects of Schedule and Gender prior to a rest break}

Results for normalized MdPF prior to a rest break are provided in Table A3. MdPF values prior to a rest break were $<1$, which overall indicates accumulated fatigue in all three schedules. For most muscles, especially those in forearm and upper arm, values were higher in the Long-break and Self-selected conditions, suggesting less fatigue prior to a break, though differences were quite small and there were no significant main effects of either Schedule or Gender for any of the muscles. There were, however, several Schedule $\times$ Gender interactions effects that were either significant or approached significance (Figure 4). Females generally had higher values of normalized MdPF, suggesting less fatigue. Though gender differences were not significant, higher values among females were observed for the $\mathrm{AD}(p=0.254$, difference $=2.9 \%), \mathrm{MD}$ $(p=0.270$, difference $=3.3 \%), \operatorname{PD}(p=0.051$, difference $=4.3 \%)$, and UT $(p=0.195$, difference $=3.9 \%$ ) in the Long-break condition. Higher values, again non-significant, were also 
observed among females for the $\mathrm{AD}(p=0.236$, difference $=2.4 \%)$ and $\mathrm{MD}(p=0.108$, difference $=4.0 \%$ ) in the Short-break condition, and in the UT in the Self-selected condition ( $p=0.081$, difference $=5.1 \%)$. Higher values for males were only evident in the Self-selected condition for the $\mathrm{AD}$, though this was also non-significant ( $p=0.061$, difference $=-4.6 \%$ ).
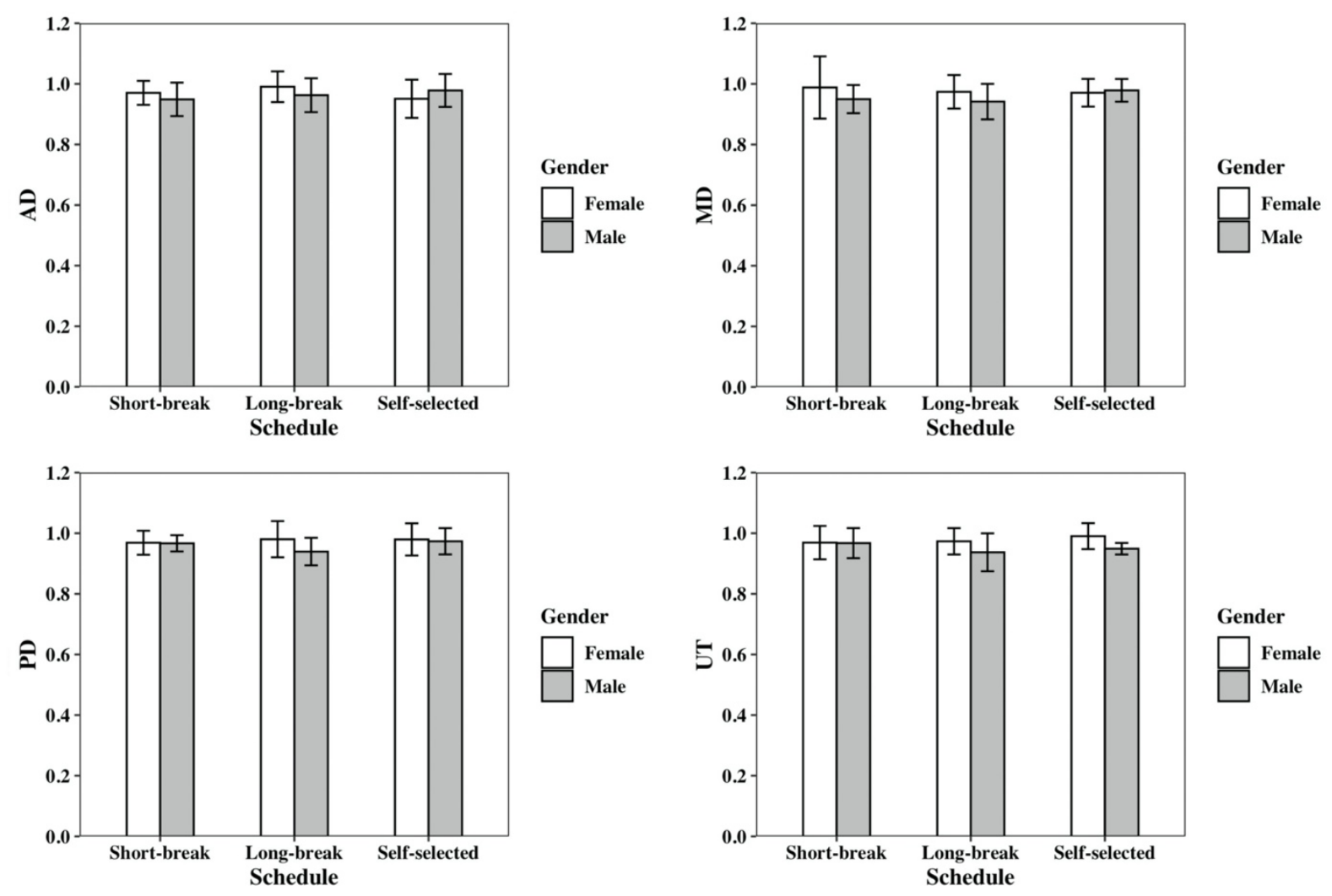

Figure 4. Interactive effects of Schedule and Gender on normalized MdPF of the AD, MD, PD, and UT muscles prior to a rest break.

Performance measures are summarized in Table A4. The Short-break condition led to both more errors and faster speed in the assembly task, while the opposite occurred for the Long-break condition. In the maze tracking task, the Self-selected condition had the fewest errors and fastest 
speed. No main or interactive effects of Schedule were significant, however. There was a significant difference between genders in assembly errors, which were higher among males.

\subsection{Effects of Schedule and Gender after a rest break}

Results for normalized MdPF after a rest are provided in Table A5. Comparing Tables A3 and A5, MdPF values prior to a rest break were usually lower than those after a rest break, which respectively indicate accumulated fatigue and recovery before and after a rest break. Significant differences were found between Genders for ECR and ECU. For both muscles, values were higher among females. For most muscles, values were higher in the Long-break and Selfselected conditions, suggesting less fatigue after a break, though differences were quite small and there were no significant effects of Schedule for most muscles. As an exception, the main effect of Schedule was significant on ECR. There were several Schedule $\times$ Gender interaction effects that were significant or approached significance (Figure 5). Females generally had slightly higher values of MdPF, suggesting less fatigue, which was significant for the ECR ( $p=0.035$, difference $=3.1 \%)$, though non-significant for the $\mathrm{FCR}(p=0.073$, difference $=5.3 \%), \mathrm{AD}$ $(p=0.054$, difference $=4.0 \%)$, and $\mathrm{MD}(p=0.211$, difference $=3.9 \%)$ in the Short-break condition . Significantly higher values were also observed for the $\mathrm{AD}(p=0.048$, difference $=5.7 \%)$ and $\mathrm{PD}$ ( $p=0.039$, difference $=6.8 \%)$ in the Long-break condition, and there were similar though nonsignificant differences in the MD as well ( $p=0.094$, difference $=7.5 \%)$. In the Self-selected condition, females had higher values of MdPF for the ECR that approached significance ( $p=0.065$, difference $=3.2 \%$ ) while males had slightly higher (though non-significant) values for the FCR $(p=0.254$, difference $=-4.0 \%)$. 

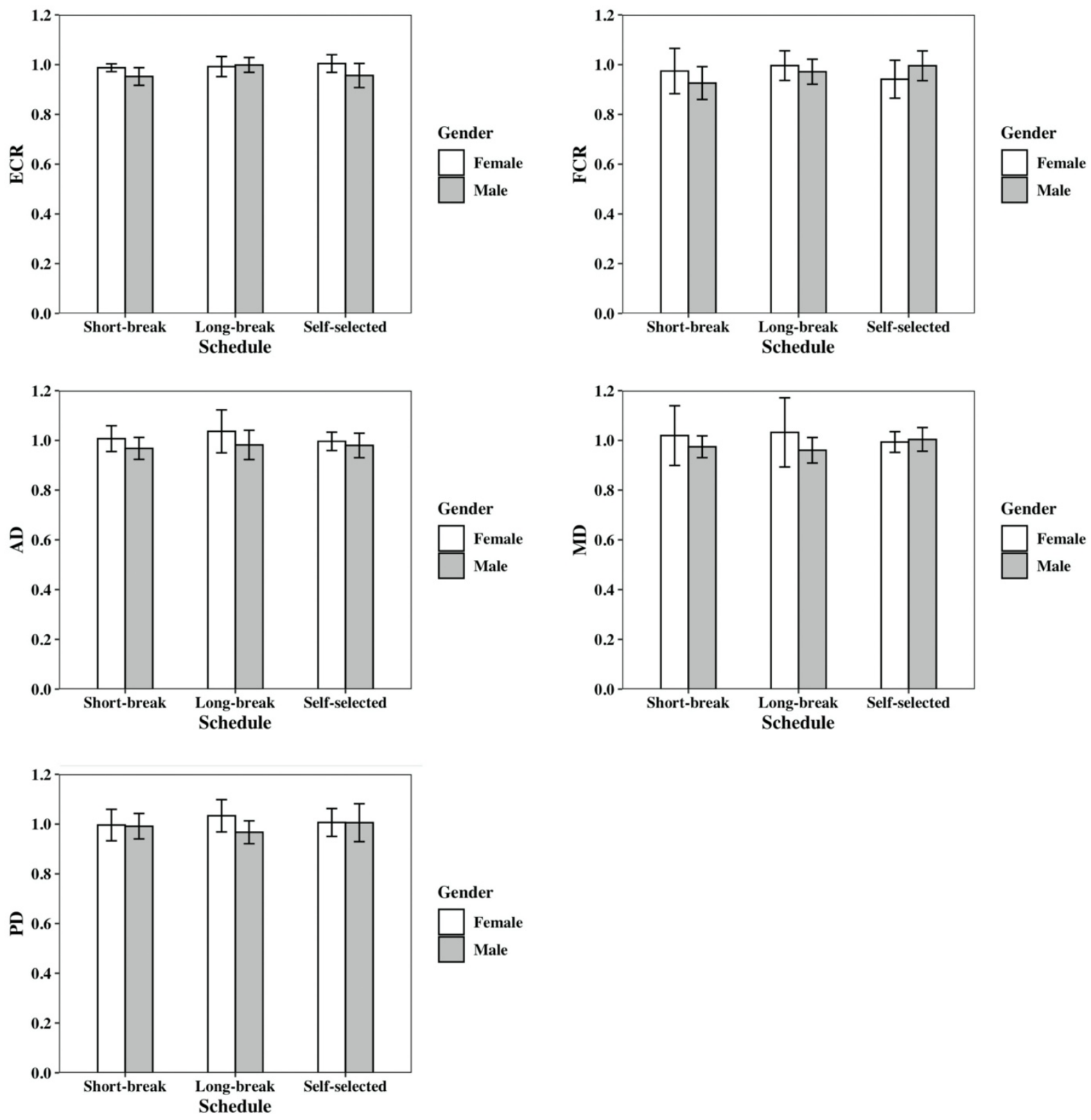

Figure 5. Interactive effects of Schedule and Gender on normalized MdPF of the ECR, FCR, $\mathrm{AD}, \mathrm{MD}$, and PD muscles after a rest break.

Performance measures right after a rest break are summarized in Table A6. A significant effect of Schedule was found on maze speed. Participants were $7.2 \%$ faster in the Short-break than in the Long-break condition, and were $8.5 \%$ faster in the Self-selected than in the Long-break 
condition. There were also fewer errors in both the assembly and maze tracking tasks during the Short-break condition, and assembly speed was higher in the Long-break condition, though neither of these differences were significant.

\section{4. $R P D$ s and $W / R$ Schedule Rankings}

Final RPD ratings are summarized in Table A7. While there were no significant effects of Schedule or Gender, a consistent pattern of responses was evident across all five body parts. Specifically, RPDs were highest in the Short-break condition and lowest in the Long-break condition. Rankings of the three schedules are summarized in Table 2. There was a significant difference in rankings among schedules $\left(\chi^{2}=8.015, d f=2, p=0.018\right)$. Specifically, the Short-break condition was slightly preferred over the Long-break condition $(p=0.052)$ and the Self-selected condition was preferred over the Long-break condition $(p=0.026)$. The difference in preference between the Short-break and the Self-selected conditions was not significant.

Table 2. Results for rankings of the three schedules $\left(1^{\text {st }}=\right.$ most preferred $)$. The number (percentage) of rankings are presented.

\begin{tabular}{lllll}
\hline \multirow{2}{*}{ Schedule } & \multicolumn{2}{l}{ Number of rankings as: } & \multirow{2}{*}{ Mean Ridit } \\
\cline { 2 - 4 } & $1^{\text {st }}$ & $2^{\text {nd }}$ & $3^{\text {rd }}$ & \multirow{2}{*}{0.444} \\
Short-break & 8 & 5 & 5 & \\
Long-break & $(44.4 \%)$ & $(27.8 \%)$ & $(27.8 \%)$ & 0.648 \\
Self-selected & 3 & 4 & 11 & \\
& $(16.7 \%)$ & $(22.2 \%)$ & $(61.1 \%)$ & \multirow{2}{*}{0.407} \\
\hline
\end{tabular}




\section{Discussion}

This exploratory study examined the effects of different $\mathrm{W} / \mathrm{R}$ schedules on muscle fatigue, task performance, and preference in repetitive precision tasks. Contrary to our expectation, participants appeared to have more muscular fatigue in the Short-break condition compared with both the Long-break and the Self-selected conditions. Our other expectations were supported, in that participants most preferred the Self-selected condition and the different schedules did not influence task performance. Furthermore, females appeared to develop less localized fatigue in certain muscles in some $\mathrm{W} / \mathrm{R}$ schedules.

\subsection{Effects of $W / R$ schedule on physical and subjective fatigue}

Although W/R schedule did not significantly influence muscle fatigue overall, participants seemed to experience less fatigued in the forearm and upper arm muscles in the Long-break and Self-selected conditions (see Tables A1, A3, and A5). This outcome contradicts some previous studies, in which participants exhibited less fatigue (or better recovery) with more frequent task rotation or a short W/R cycle (Horton et al., 2012; Lin et al., 2012; Rashedi \& Nussbaum, 2016; Wawrow et al., 2011). RPDs here also demonstrated a similar tendency, in that participants reported the least fatigue in some body regions in a Long-break condition, and moderate fatigue in a Self-selected condition.

The discrepancy in findings between our study and earlier ones may have resulted from differences in the tasks involved, given that task type can mediate the influence of W/R schedules on fatigue and performance (Balci \& Aghazadeh, 2003; Balogh et al., 2016; Dickerson et al., 2015; Januario et al., 2016). Compared to earlier work, our study involved more precise 
movements and required coordination of several muscle groups. In contrast, Horton et al. (2012) and Rashedi \& Nussbaum (2016) examined repetitive isometric abductions of relatively isolated body parts. Further, EMG from only a single muscle was used as a fatigue indicator in these two studies, whereas multiple muscles involved in the current tasks were monitored. In other work, relatively simple movements or tasks were also involved (Lin et al., 2012; Wawrow et al., 2011). It is also worth noting that the overall $\mathrm{W} / \mathrm{R}$ ratio here was 10:1 in each the three of the schedules, which allowed somewhat less rest compared with previous studies. For example, the W/R ratio was set as 10:3 in Lin et al. (2012), and in Rashedi \& Nussbaum (2016) the duty cycle was 50\% (i.e., a $\mathrm{W} / \mathrm{R}$ ratio of 1:1). With the increased proportion of work and the reduced rest time in our study, in the Short-break condition the rest may have limited recovery, thereby leading to the discrepant influence of the $\mathrm{W} / \mathrm{R}$ schedules on fatigue.

\section{2. $\quad$ Preference among $W / R$ schedules}

A notable finding is that in the Long-break condition participants exhibited less fatigue based on EMG, but this schedule was (significantly) the least preferred one. Instead, the Self-selected condition had the highest preference and the Short-break condition was supported moderately (Table 2). Micro-breaks can provide an immediate feeling of relief (Byström, et al., 1991) and increased mental focus (Park et al., 2017), which might have contributed to the higher preference of the participants for the Short-break condition.

Previous work has indicated that a self-selected W/R schedule can contribute to higher job satisfaction and a sense of job control (Luger et al., 2016; Stålhammar et al., 1992); such outcomes could explain the clear preference here for the Self-selected condition. To assess this 
issue in more detail, we compiled comments from the participants on their $\mathrm{W} / \mathrm{R}$ strategies. Three types of strategies emerged, as summarized below (the number of participants choosing each strategy is listed in parentheses, and some participants indicated multiple strategies):

1) Consider the effects of fatigue/discomfort (10): Participants considered their level of physical fatigue, mental fatigue, and eye strain to determine when to rest. The rest duration used was associated with their feelings of recovery, and they only went back to work when they felt sufficiently recovered.

2) Fixed W/R pace (9): Participants created a fixed W/R pattern in advance, before conducting the task, and then followed the pattern (e.g., rest after every 40-50 replications). Some participants in this category did not rest very much in the initial 10min period, then created a more frequent rest pattern in the second half to overcome accumulated fatigue.

3) Consider performance (7): Note that participants were instructed to finish the tasks as accurately and as fast as possible, and that accuracy should be the primary concern. Participants could easily detect their errors during the assembly/disassembly task, which may explain why they noted that infrequent rest breaks with longer work periods could increase accuracy in this task. They indicated that overall assembly/disassembly errors, and errors prior to a rest break, were likely fewer in the Long-break condition, which corresponded with the actual outcomes (as indicated in Tables A2 and A4). Comparing Tables A2 and A6, it was evident that task accuracy dropped immediately after a rest break. Therefore, it appears that participants chose to work for a long period without 
breaks to maintain a high level of performance, and then rest for a long period. They also reported believing that a longer rest period would lead to a stronger feeling of recovery.

As one example, a male participant noted that frequent breaks helped him with hand muscle recovery and eye strain relief, and he thus chose a strategy involving frequent and short breaks that was a mix of the first two strategies listed above. As an example of the third strategy, both a female participant and a different male participant commented that their performance decreased substantially after frequent rest, so they opted to work for a prolonged period to accumulate experience and to become familiar with the required movements. Note that among the nine participants who had fixed W/R paces, two used three types of strategies simultaneously (i.e., considering jointly the effects of fatigue/discomfort, fixed pace, and task performance); five considered only the effects of fatigue; and two considered task performance. One participant did not recall using a specific strategy for the Self-selected condition.

To gain additional insight, the number and duration of rest breaks taking during the Self-selected condition were examined. In this condition, participants rested a mean of 3.9 times $(\mathrm{SD}=3.1$, median $=3.5$ times $)$, with a mean duration of $96.0 \mathrm{sec} .(\mathrm{SD}=7.8$, median $=70.0)$. With a fixed total rest break of 4 minutes, this mean rest duration is much longer than the Short-break condition (i.e., $30 \mathrm{sec}$. for each break) and slightly shorter than in the Long-break condition (i.e., $120 \mathrm{sec}$.). The $96.0 \mathrm{sec}$. of rest that was self-selected was closer to the rest duration in the Longbreak condition, and thus may have provide sufficient (or at least better) recovery from muscle fatigue recovery compared to the Short-break condition. The "actual" physical recovery together 
with the "feeling" of job control may have contributed to the higher preference for the Selfselected condition.

\subsection{Effects of $W / R$ Schedule on task performance}

As noted above, there were no statistically-significant differences in task performance among the three $\mathrm{W} / \mathrm{R}$ schedules. This lack of an effect agrees with previous work showing that introducing breaks, regardless of length and duration, did not significantly influence precision task performance (Hallbeck et al., 2017; Komorowski et al., 2015; Lin et al., 2012; McLean et al., 2001). We found some evidence of differences between schedules in specific performance measures, but these effects were not consistent (see Table 3, a summary of the influences of schedules on performance measure in the three $\mathrm{W} / \mathrm{R}$ schedules). In the Long-break condition, participants were better at maintaining accuracy in the assembly/disassembly task, both overall and when measured prior to a rest break. This evidence is in accordance with findings of Henning et al. (1989), that after longer breaks a data entry correction rate was lower than after short breaks (i.e., better accuracy). However, in the Self-selected and Short-break conditions here, accuracy was higher, and speed was faster in the maze tracking task, but the accuracy of assembly/disassembly was somewhat compromised. These outcomes may suggested a balance between forgetting and familiarization with the task (Globerson et al., 1989). 
Table 3. Summary of performance measures in the three W/R schedules. Note that the three conditions are ordered "better" to "worse" performance for each outcome measure.

\begin{tabular}{llll}
\hline Measure & Overall & Prior to a rest & After a rest \\
\hline Assembly Error & Long $<$ Short $=$ Self & Long $<$ Self $<$ Short & Short $<$ Long $<$ Self \\
Assembly Speed & Self $=$ Short $>$ Long & Short $>$ Self $>$ Long & Long $>$ Short $>$ Self \\
Maze Error & Short $<$ Self $<$ Long & Self $<$ Long $<$ Short & Short $<$ Self $<$ Long \\
Maze Speed & Self $>$ Short $>$ Long & Self $>$ Short $>$ Long & Self $>$ Short $>$ Long \\
\hline
\end{tabular}

\subsection{Gender differences in fatigue and task performance}

Female participants here experienced less fatigue in specific upper-extremity muscles, based on normalized MPDF results (the pattern of results was consistent across several muscles, though several gender differences only approached significance). Females also performed better in the assembly task, with better accuracy. These were consistent with results of Horton et al. (2012). The current tasks involved minimal dynamic components, and as such the noted gender difference in fatigue is consistent with earlier work of a relative fatigue resistance among females during isometric contractions (e.g., Hunter \& Enoka, 2001). There are also gender differences in motor control. For example, in a repetitive upper-extremity task Srinivasan et al. (2016) found that female participants tended to employ an elbow-based strategy, whereas males used their shoulders more. Though not quantified, similar differences may have occurred here and contributed to the lesser fatigue (e.g., in ECR and FCR) and higher performance among females. Although females have been reported to have less variation in force generation (Gaudez et al., 2016), there has not been a consistent conclusion on the relationship between muscle activity variation and muscle fatigue (Luger et al., 2014; Rodriguez \& Barrero, 2017). While the above arguments help to explain some of the current differences found between genders, it remains unclear why these gender differences were inconsistent across the three $\mathrm{W} / \mathrm{R}$ scheduled. Specifically: 1) why there were interactive effects of Schedule $\times$ Gender on muscle fatigue; and, 
2) why males had marginally higher MdPF in the AD after a rest break in the Self-selected condition.

\subsection{Limitations, implications, and future work}

Among all of outcome measures obtained here, only RPD and schedule preference showed consistent or statistically significant results. Psychological measures overall appear to be more sensitive to differences in work patterns, as indicated in previous studies (Luger et al., 2015; Padula et al., 2017; Ringheim et al., 2014). Furthermore, the levels of muscle activation here were relatively low, and we may have not induced sufficient levels of fatigue to yield clear results. In such situations, EMG-based measures in particular can yield relatively insensitive metrics of muscle fatigue (Nagata et al., 1990; Nargol et al., 1999; Öberg et al., 1994; Sood et al., 2007). Thus, a more comprehensive set of fatigue and performance measures should be developed to better quantify the influences of work patterns on fatigue and task performance (Padula et al., 2017; Yung et al., 2014), and future studies may consider to induce higher levels of fatigue and/or use a longer total work duration. For the three strategies that emerged in the Self-selected condition, we only focused on words/comments related to "fatigue/discomfort", “performance", and "pace”. A more formal qualitative data analysis may provide a more reliable explanation for the classified types.

An important limitation of our study was that participants were all novices and not familiar or experienced with actual repetitive, precision occupational tasks. Whether the current results would be found among workers in situ is unknown. In addition, we only monitored muscle fatigue, performance, and preferences in response to a relatively short work duration (i.e., 40 
min.). Longer-term testing is clearly needed to better understand the effects of $\mathrm{W} / \mathrm{R}$ schedules. It should also be noted that in practice - especially on an assembly line where strict antecedentconsequent task order and strict line-balancing are required - some restrictions to a self-selected schedule may be needed to ensure line-balancing.

The results of this exploratory study suggest that during repetitive precision tasks workers may experience less muscle fatigue with long work periods together with long, infrequent rest periods, without sacrificing task performance. However, feelings of job satisfaction and control, which can be enhanced with a Self-selected schedule, should not be ignored. Overall, the Selfselected condition here appeared to provide several benefits, in terms of task performance, fatigue recovery, and preference. As such, the use of short breaks may be less welcomed or effective in practice. However, earlier work suggests that muscle responses in low-exertion tasks can be task-specific (Clark et al., 2003; Hunter, 2015; Srinivasan et al., 2016); as such, the current results, using only a simulated task in a controlled setting, need to be interpreted with some caution.

\section{Acknowledgments}

The work reported here was supported in part by: the Chinese Scholarship Council, the National Natural Science Foundation of China under Grant 71942005; and the Wisdom Gathered in Zhengzhou 1125 Talents Recruitment Program. Opinions expressed herein do not necessarily represent those of any of these agencies. The authors thank Quan Yuan and Yining Wu for their help in developing the Android application. This study was completed when the first author was a visiting $\mathrm{PhD}$ student at Virginia Tech. 


\section{References}

Al-Mulla, M. R., Sepulveda, F., \& Colley, M. (2011). A Review of Non-Invasive Techniques to Detect and Predict Localised Muscle Fatigue. Sensors, 11(12), 3545-3594. https://doi.org/10.3390/s110403545

Armstrong, T. J., Buckle, P., Fine, L. J., Hagberg, M., Jonsson, B., Kilbom, A., Kuorinka, I. A., Silverstein, B. A., Sjogaard, G., \& Viikari-Juntura, E. R. (1993). A conceptual model for work-related neck and upper-limb musculoskeletal disorders. Scandinavian Journal of Work, Environment \& Health, 73-84.

Balci, R., \& Aghazadeh, F. (2003). The effect of work-rest schedules and type of task on the discomfort and performance of VDT users. Ergonomics, 46(5), 455-465. https://doi.org/10.1080/0014013021000047557

Balogh, I., Ohlsson, K., Nordander, C., Björk, J., \& Hansson, G.-Å. (2016). The importance of work organization on workload and musculoskeletal health - Grocery store work as a model. Applied Ergonomics, 53, 143-151. https://doi.org/10.1016/j.apergo.2015.09.004

Bechtold, S. E. (1991). Optimal Work-Rest Schedules with a Set of Fixed-Duration Rest Periods. Decision Sciences, 22(1), 157-170. https://doi.org/10.1111/j.1540-5915.1991.tb01268.x

Borg, G. (1998). Borg's perceived exertion and pain scales. Human kinetics.

Bosch, T., Mathiassen, S. E., Visser, B., Looze, M. P. de, \& Dieën, J. H. van. (2011). The effect of work pace on workload, motor variability and fatigue during simulated light assembly work. Ergonomics, 54(2), 154-168. https://doi.org/10.1080/00140139.2010.538723

Bureau of Labor Statistics. (2020). Occupational injuries and illnesses resulting in musculoskeletal disorders (MSDs). https://www.bls.gov/iif/oshwc/case/msds.htm

Byström, S. E. G., Mathiassen, S. E., \& Fransson-Hall, C. (1991). Physiological effects of micropauses in isometric handgrip exercise. European Journal of Applied Physiology and Occupational Physiology, 63(6), 405-411. https://doi.org/10.1007/BF00868070

Chaikumarn, M., Nakphet, N., \& Janwantanakul, P. (2018). Impact of rest-break interventions on the neck and shoulder posture of symptomatic VDU operators during prolonged computer work. International Journal of Occupational Safety and Ergonomics, 24(2), 251-259. https://doi.org/10.1080/10803548.2016.1267469

Clark, B. C., Manini, T. M., Thé, D. J., Doldo, N. A., \& Ploutz-Snyder, L. L. (2003). Gender differences in skeletal muscle fatigability are related to contraction type and EMG spectral compression. J Appl Physiol, 94, 10.

Crenshaw, A. G., Djupsjöbacka, M., \& Svedmark, Å. (2006). Oxygenation, EMG and position sense during computer mouse work. Impact of active versus passive pauses. European Journal of Applied Physiology, 97(1), 59-67. https://doi.org/10.1007/s00421-006-0138-4

Crook, J., Milner, R., Schultz, I. Z., \& Stringer, B. (2002). Determinants of Occupational Disability Following a Low Back Injury: A Critical Review of the Literature. Journal of Occupational Rehabilitation, 12(4), 277-295. https://doi.org/10.1023/A:1020278708861

de Kok, J., Vroonhof, P., Snijders, J., Roullis, G., Clarke, M., Peereboom, K., \& van Dorst, P. (2019). Work-related MSDs: Prevalence, costs and demographics in the EU (p. 18).

Dennerlein, J. T., Ciriello, V. M., Kerin, K. J., \& Johnson, P. W. (2003). Fatigue in the Forearm Resulting From Low-Level Repetitive Ulnar Deviation. AIHA Journal, 64(6), 799-805. https://doi.org/10.1080/15428110308984875

Dickerson, C. R., Meszaros, K. A., Cudlip, A. C., Chopp-Hurley, J. N., \& Langenderfer, J. E. (2015). The influence of cycle time on shoulder fatigue responses for a fixed total 
overhead workload. Journal of Biomechanics, 48(11), 2911-2918.

https://doi.org/10.1016/j.jbiomech.2015.04.043

Dorion, D., \& Darveau, S. (2013). Do Micropauses Prevent Surgeon's Fatigue and Loss of Accuracy Associated With Prolonged Surgery? An Experimental Prospective Study. Annals of Surgery, 257(2), 256. https://doi.org/10.1097/SLA.0b013e31825efe87

Endo, H., \& Kawahara, K. (2011). Gender differences in hand stability of normal young people assessed at low force levels. Ergonomics, 54(3), 273-281. https://doi.org/10.1080/00140139.2010.547607

Falla, D., \& Farina, D. (2007). Periodic increases in force during sustained contraction reduce fatigue and facilitate spatial redistribution of trapezius muscle activity. Experimental Brain Research, 182(1), 99-107. https://doi.org/10.1007/s00221-007-0974-4

Gates, D. H., \& Dingwell, J. B. (2008). The effects of neuromuscular fatigue on task performance during repetitive goal-directed movements. Experimental Brain Research, 187(4), 573-585. https://doi.org/10.1007/s00221-008-1326-8

Gaudez, C., Gilles, M. A., \& Savin, J. (2016). Intrinsic movement variability at work. How long is the path from motor control to design engineering? Applied Ergonomics, 53, 71-78. https://doi.org/10.1016/j.apergo.2015.08.014

Genaidy, A. M., Delgado, E., \& Bustos, T. (1995). Active microbreak effects on musculoskeletal comfort ratings in meatpacking plants. Ergonomics, 38(2), 326-336. https://doi.org/10.1080/00140139508925107

Globerson, S., Levin, N., \& Shtub, A. (1989). The Impact of Breaks on Forgetting When Performing A Repetitive Task. IIE Transactions, 21(4), 376-381. https://doi.org/10.1080/07408178908966244

Hallbeck, M. S., Lowndes, B. R., Bingener, J., Abdelrahman, A. M., Yu, D., Bartley, A., \& Park, A. E. (2017). The impact of intraoperative microbreaks with exercises on surgeons: A multi-center cohort study. Applied Ergonomics, 60, 334-341. https://doi.org/10.1016/j.apergo.2016.12.006

Henning, R. A., Sauter, S. L., Salvendy, G., \& Krieg, E. F. (1989). Microbreak length, performance, and stress in a data entry task. Ergonomics, 32(7), 855-864. https://doi.org/10.1080/00140138908966848

Hermens, H. J., Freriks, B., Disselhorst-Klug, C., \& Rau, G. (2000). Development of recommendations for SEMG sensors and sensor placement procedures. Journal of Electromyography and Kinesiology, 10(5), 361-374. https://doi.org/10.1016/S10506411(00)00027-4

Horton, L. M., Nussbaum, M. A., \& Agnew, M. J. (2012). Effects of rotation frequency and task order on localised muscle fatigue and performance during repetitive static shoulder exertions. Ergonomics, 55(10), 1205-1217. https://doi.org/10.1080/00140139.2012.704406

Hunter, S. K. (2015). Sex Differences in Human Fatigability: Mechanisms and Insight to Physiological Responses. Acta Physiol, 37.

Hunter, S. K., \& Enoka, R. M. (2001). Sex differences in the fatigability of arm muscles depends on absolute force during isometric contractions. J Appl Physiol, 91, 9.

Ivarsson, A., \& Eek, F. (2016). The relationship between physical workload and quality within line-based assembly. Ergonomics, 59(7), 913-923. https://doi.org/10.1080/00140139.2015.1105303 
Januario, L. B., Madeleine, P., Cid, M. M., Samani, A., \& Oliveira, A. B. (2018). Can exposure variation be promoted in the shoulder girdle muscles by modifying work pace and inserting pauses during simulated assembly work? Applied Ergonomics, 66(Supplement C), 151-160. https://doi.org/10.1016/j.apergo.2017.08.011

Januario, L. B., Moreira, R. de F. C., Cid, M. M., Samani, A., Madeleine, P., \& Oliveira, A. B. (2016). Effects of active pause pattern of surface electromyographic activity among subjects performing monotonous tasks: A systematic review. Journal of Electromyography and Kinesiology, 30(Supplement C), 196-208. https://doi.org/10.1016/j.jelekin.2016.07.009

Komorowski, A. L., Usero, D. D., Rodil, J. R. M., \& Topór-M?dry, R. (2015). The Influence of Micropauses on Surgeons' Precision After Short Laparoscopy Procedures. Polish Journal of Surgery, 87(3).

Leider, P. C., Boschman, J. S., Frings-Dresen, M. H. W., \& Molen, H. F. van der. (2015). Effects of job rotation on musculoskeletal complaints and related work exposures: A systematic literature review. Ergonomics, 58(1), 18-32. https://doi.org/10.1080/00140139.2014.961566

Lin, J.-H., McGorry, R. W., \& Maikala, R. V. (2012). The effects of joint torque, pace and work:rest ratio on powered hand tool operations. Ergonomics, 55(3), 361-370. https://doi.org/10.1080/00140139.2011.639905

Lu, L., Megahed, F. M., \& Cavuoto, L. A. (2021). Interventions to Mitigate Fatigue Induced by Physical Work: A Systematic Review of Research Quality and Levels of Evidence for Intervention Efficacy. Human Factors: The Journal of the Human Factors and Ergonomics Society, 63(1), 151-191. https://doi.org/10.1177/0018720819876141

Luger, T., Bosch, T., Hoozemans, M., de Looze, M., \& Veeger, D. (2015). Task variation during simulated, repetitive, low-intensity work - influence on manifestation of shoulder muscle fatigue, perceived discomfort and upper-body postures. Ergonomics, 58(11), 1851-1867. https://doi.org/10.1080/00140139.2015.1043356

Luger, T., Bosch, T., Hoozemans, M. J. M., Veeger, D. H. E. J., \& de Looze, M. P. (2016). Is rotating between static and dynamic work beneficial for our fatigue state? Journal of Electromyography and Kinesiology, 28, 104-113. https://doi.org/10.1016/j.jelekin.2016.04.001

Luger, T., Bosch, T., Veeger, D., \& de Looze, M. (2014). The influence of task variation on manifestation of fatigue is ambiguous - a literature review. Ergonomics, 57(2), 162-174. https://doi.org/10.1080/00140139.2014.885088

Luger, T., Mathiassen, S. E., Srinivasan, D., \& Bosch, T. (2017). Influence of Work Pace on Upper Extremity Kinematics and Muscle Activity in a Short-Cycle Repetitive Pick-andPlace Task. Annals of Work Exposures and Health, 61(3), 356-368. https://doi.org/10.1093/annweh/wxx001

Mark Burden, A., Lewis, S. E., \& Willcox, E. (2014). The effect of manipulating root mean square window length and overlap on reliability, inter-individual variability, statistical significance and clinical relevance of electromyograms. Manual Therapy, 19(6), 595601. https://doi.org/10.1016/j.math.2014.06.003

Mathiassen, S. E., \& Winkel, J. (1992). Can occupational guidelines for work-rest schedules be based on endurance time data? Ergonomics, 35(3), 253-259. https://doi.org/10.1080/00140139208967811 
Mathiassen, Svend Erik. (2006). Diversity and variation in biomechanical exposure: What is it, and why would we like to know? Applied Ergonomics, 37(4), 419-427.

https://doi.org/10.1016/j.apergo.2006.04.006

McLean, L., Tingley, M., Scott, R. N., \& Rickards, J. (2001). Computer terminal work and the benefit of microbreaks. Applied Ergonomics, 32(3), 225-237. https://doi.org/10.1016/S0003-6870(00)00071-5

Mehta, J. P., Lavender, S. A., Jagacinski, R. J., \& Sommerich, C. M. (2015). Effects of Task Precision Demands on Behavioral and Physiological Changes During a Repetitive Asymmetric Lifting Activity. Human Factors: The Journal of the Human Factors and Ergonomics Society, 57(3), 435-446. https://doi.org/10.1177/0018720814551556

Merletti, R., \& Farina, D. (Eds.). (2016). Surface electromyography: Physiology, engineering and applications. IEEE Press ; Wiley.

Nagata, S., Arsenault, A. B., Gagnon, D., Smyth, G., \& Mathieu, P.-A. (1990). EMG power spectrum as a measure of muscular fatigue at different levels of contraction. Medical \& Biological Engineering \& Computing, 28(4), 374-378. https://doi.org/10.1007/BF02446157

Nargol, A. V. F., Jones, A. P. C., Kelly, P. J., \& Greenough, C. G. (1999). Factors in the reproducibility of electromyographic power spectrum analysis of lumbar paraspinal muscle fatigue. Spine, 24(9), 883-888.

Neumann, W. P., Kolus, A., \& Wells, R. W. (2016). Human Factors in Production System Design and Quality Performance - A Systematic Review. IFAC-PapersOnLine, 49(12), 1721-1724. https://doi.org/10.1016/j.ifacol.2016.07.830

Öberg, T., SANDSJö, L., \& Kadefors, R. (1994). Subjective and objective evaluation of shoulder muscle fatigue. Ergonomics, 37(8), 1323-1333. https://doi.org/10.1080/00140139408964911

OSHA. (2001, June). Poultry Processing Industry eTool. Poultry Processing Industry ETool. https://www.osha.gov/SLTC/etools/poultry/general_hazards/ergonomics.html

OSHA. (2003, August). Computer Workstations eTool. Computer Workstations ETool. https://www.osha.gov/SLTC/etools/computerworkstations/workprocess.html

Padula, R. S., Comper, M. L. C., Sparer, E. H., \& Dennerlein, J. T. (2017). Job rotation designed to prevent musculoskeletal disorders and control risk in manufacturing industries: A systematic review. Applied Ergonomics, 58, 386-397. https://doi.org/10.1016/j.apergo.2016.07.018

Paquet, V., \& Nirmale, R. (2004). Trunk Flexion and Musculoskeletal Stress during Light Assembly Work. Journal of Applied Biomechanics, 20(3), 230-242. https://doi.org/10.1123/jab.20.3.230

Park, A. E., Zahiri, H. R., Hallbeck, M. S., Augenstein, V., Sutton, E., Yu, D., Lowndes, B. R., \& Bingener, J. (2017). Intraoperative "Micro Breaks" With Targeted Stretching Enhance Surgeon Physical Function and Mental Focus: A Multicenter Cohort Study. Annals of Surgery, 265(2), 340-346. https://doi.org/10.1097/SLA.0000000000001665

Phinyomark, A., Thongpanja, S., Hu, H., Phukpattaranont, P., \& Limsakul, C. (2012). The Usefulness of Mean and Median Frequencies in Electromyography Analysis. In G. R. Naik (Ed.), Computational Intelligence in Electromyography Analysis-A Perspective on Current Applications and Future Challenges. InTech. https://doi.org/10.5772/50639

R Core Team. (2020). R: A Language and Environment for Statistical Computing. R Foundation for Statistical Computing. https://www.R-project.org/ 
Rajabalipour Cheshmehgaz, H., Haron, H., Kazemipour, F., \& Desa, M. I. (2012). Accumulated risk of body postures in assembly line balancing problem and modeling through a multicriteria fuzzy-genetic algorithm. Computers \& Industrial Engineering, 63(2), 503-512. https://doi.org/10.1016/j.cie.2012.03.017

Rashedi, E., \& Nussbaum, M. A. (2016). Cycle time influences the development of muscle fatigue at low to moderate levels of intermittent muscle contraction. Journal of Electromyography and Kinesiology, 28, 37-45. https://doi.org/10.1016/j.jelekin.2016.03.001

Ringheim, I., Indahl, A., \& Roeleveld, K. (2014). Alternating activation is related to fatigue in lumbar muscles during sustained sitting. Journal of Electromyography and Kinesiology, 24(3), 380-386. https://doi.org/10.1016/j.jelekin.2014.01.011

Rodriguez, A. C., \& Barrero, L. H. (2017). Job rotation: Effects on muscular activity variability. Applied Ergonomics, 60, 83-92. https://doi.org/10.1016/j.apergo.2016.11.005

Rosa, R. R., Bonnet, M. H., \& Cole, L. L. (1998). Work Schedule and Task Factors in UpperExtremity Fatigue. Human Factors: The Journal of the Human Factors and Ergonomics Society, 40(1), 150-158. https://doi.org/10.1518/001872098779480523

Samani, A., Holtermann, A., Søgaard, K., \& Madeleine, P. (2009). Active pauses induce more variable electromyographic pattern of the trapezius muscle activity during computer work. Journal of Electromyography and Kinesiology, 19(6), e430-e437. https://doi.org/10.1016/j.jelekin.2008.11.011

Samani, A., Holtermann, A., Søgaard, K., \& Madeleine, P. (2010). Active biofeedback changes the spatial distribution of upper trapezius muscle activity during computer work. European Journal of Applied Physiology, 110(2), 415-423. https://doi.org/10.1007/s00421-010-1515-6

Søgaard, K., Blangsted, A. K., Jørgensen, L. V., Madeleine, P., \& Sjøgaard, G. (2003). Evidence of long term muscle fatigue following prolonged intermittent contractions based on mechano- and electromyograms. Journal of Electromyography and Kinesiology, 13(5), 441-450. https://doi.org/10.1016/S1050-6411(03)00075-0

Sood, D., Nussbaum, M. A., \& Hager, K. (2007). Fatigue during prolonged intermittent overhead work: Reliability of measures and effects of working height. Ergonomics, 50(4), 497513. https://doi.org/10.1080/00140130601133800

Srinivasan, D., Samani, A., Mathiassen, S. E., \& Madeleine, P. (2015). The size and structure of arm movement variability decreased with work pace in a standardised repetitive precision task. Ergonomics, 58(1), 128-139. https://doi.org/10.1080/00140139.2014.957736

Srinivasan, D., Sinden, K. E., Mathiassen, S. E., \& Côté, J. N. (2016). Gender differences in fatigability and muscle activity responses to a short-cycle repetitive task. European Journal of Applied Physiology, 116(11-12), 2357-2365. https://doi.org/10.1007/s00421016-3487-7

Stålhammar, H. R., Leskinen, T. P. J., Rautanen, M. T., \& Troup, J. D. G. (1992). Shrinkage and psychophysical load ratings in self-paced and force-paced lifting work and during recovery. Ergonomics, 35(1), 1-5. https://doi.org/10.1080/00140139208967793

Sundelin, G., \& Hagberg, M. (1989). The effects of different pause types on neck and shoulder EMG activity during VDU work. Ergonomics, 32(5), 527-537. https://doi.org/10.1080/00140138908966123 
Tsao, L., Ma, L., \& Wang, L. (2017). Effect of local wrist muscle fatigue on multiple assemblyrelated psychomotor skills: Human Factors and Ergonomics in Manufacturing \& Service Industries, 27(4), 210-217. https://doi.org/10.1002/hfm.20707

Tsao, L., Nussbaum, M. A., Kim, S., \& Ma, L. (2020). Modelling performance during repetitive precision tasks using wearable sensors: A data-driven approach. Ergonomics, 63(7), 831849. https://doi.org/10.1080/00140139.2020.1759700

Vijendren, A., Devereux, G., Tietjen, A., Duffield, K., Van Rompaey, V., Van de Heyning, P., \& Yung, M. (2020). The Ipswich Microbreak Technique to alleviate neck and shoulder discomfort during microscopic procedures. Applied Ergonomics, 83, 102679. https://doi.org/10.1016/j.apergo.2018.04.013

Visser, B., De Looze, M. P., De Graaff, M. P., \& Van Dieën, J. H. (2004). Effects of precision demands and mental pressure on muscle activation and hand forces in computer mouse tasks. Ergonomics, 47(2), 202-217. https://doi.org/10.1080/00140130310001617967

Wawrow, P. T., Jakobi, J. M., \& Cavanaugh, J. M. (2011). Fatigue response of rat medial longissimus muscles induced with electrical stimulation at various work/rest ratios. Journal of Electromyography and Kinesiology, 21(6), 939-946. https://doi.org/10.1016/j.jelekin.2011.08.007

Yoon, S.-Y., Ko, J., \& Jung, M.-C. (2016). A model for developing job rotation schedules that eliminate sequential high workloads and minimize between-worker variability in cumulative daily workloads: Application to automotive assembly lines. Applied Ergonomics, 55(Supplement C), 8-15. https://doi.org/10.1016/j.apergo.2016.01.011

Yung, M., Bigelow, P. L., Hastings, D. M., \& Wells, R. P. (2014). Detecting within- and between-day manifestations of neuromuscular fatigue at work: An exploratory study. Ergonomics, 57(10), 1562-1573. https://doi.org/10.1080/00140139.2014.934299

Yung, M., Manji, R., \& Wells, R. P. (2017). Exploring the relationship of task performance and physical and cognitive fatigue during a daylong light precision task. Human Factors, 0018720817717026.

Yung, M., Mathiassen, S. E., \& Wells, R. P. (2012). Variation of force amplitude and its effects on local fatigue. European Journal of Applied Physiology, 112(11), 3865-3879. https://doi.org/10.1007/s00421-012-2375-z 
Figure Captions and Alt Text

Figure 1 Caption: Illustrations of the two experimental sub-tasks; completing both sub-tasks comprised one 'work replication'. Top: maze tracking with display of remaining number of work replications and rest duration. Bottom: assembly/disassembly. For the latter, the eight distinct and sequential movements are indicated.

Figure 1 Alt Text: A maze used for the tracking task, with information on the status of the work status, and a sequence of eight movements required for a cycle of the assembly and disassembly task.

Figure 2 Caption: Configuration of the experiment. Left: participant doing maze tracking, showing surface EMG sensors on the dominant arm. Right: participant doing the assembly/disassembly task.

Figure 2 Alt Text: An experimental participant doing the maze tracking tasks and the assembly and disassembly tasks, with EMG sensors on the dominant arm.

Figure 3 Caption: Illustration of the three work/rest schedules included in the study. A: Long, infrequent rest breaks; B: Short, frequent rest breaks; and C: Self-selected rest break frequency and duration. Note that the latter varied between participants, and the illustration is provided only as an example.

Figure 3 Alt Text: Three work-rest schedules, differing in the length and frequency of rest breaks, along with a self-selected schedule.

Figure 4 Caption: Interactive effects of Schedule and Gender on normalized MdPF of the AD, $\mathrm{MD}, \mathrm{PD}$, and $\mathrm{U}$ muscles prior to a rest break.

Figure 4 Alt Text: Four bar graphs plotting the effects of schedule and gender on normalized median power frequency values of the $\mathrm{AD}, \mathrm{MD}, \mathrm{PD}$, and $\mathrm{U}$ muscles prior to a rest break.

Figure 5 Caption: Interactive effects of Schedule and Gender on normalized MdPF of the ECR, FCR, AD, MD, and PD muscles after a rest break.

Figure 5 Alt Text: Four bar graphs plotting the effects of schedule and gender on normalized median power frequency values of the $\mathrm{AD}, \mathrm{MD}, \mathrm{PD}$, and $\mathrm{U}$ muscles after a rest break. 